\title{
Editorial
}

\section{Academia and industry collaboration in dermatology research}

\author{
Srirupa Pal*
}

Head-Medical Services, Palsons Derma, Kolkata, West Bengal, India

\author{
*Correspondence: \\ Dr. Srirupa Pal, \\ E-mail: srirupapal@yahoo.co.in
}

Copyright: (C) the author(s), publisher and licensee Medip Academy. This is an open-access article distributed under the terms of the Creative Commons Attribution Non-Commercial License, which permits unrestricted non-commercial use, distribution, and reproduction in any medium, provided the original work is properly cited.

The assessment of cause of illness and new innovations to treat the illness is exciting at all point of time. Research is the key to any new innovations. The hindrance in development of new innovations can be multifaceted in terms of resources which may not only be limited to talent acquisition and financial resources. Collaborations among different stake holders in research such as industry, government and academia are important and should be encouraged by government to promote research, development and innovation. Currently biomedical researchers in the United States and from the international community are focusing increasingly on relationships between industry and academia and their effects on the conduct and results of research studies. ${ }^{1-3}$ Formerly rigidly separated research efforts in academic and industry have become increasingly transparent to each other. This transparency between industry and academia has created opportunities for more rapid translation of basic discoveries to patient needs. ${ }^{4}$ Collaborations among industry and academia can hasten the development of new technologies to clinical practice leading to significant health advancements. Collaboration between industry and academia facilitates quality research projects with identified impact objectives within a shorter time span. ${ }^{5}$

But in collaborative research it becomes imperative that the industry and academia jointly shares a responsibility to establish and adhere to standards in conducting research and reporting results. The research environment should promote open collaboration and information sharing. The major issue such as conflict of interest continues to pose challenges. The conduct and reporting of the research should be as per International guidelines. There should be a transparent disclosure of financial conflicts of interest (e.g., when presenting or publishing the research). Industry must maintain transparency and ensure access to data by researchers..$^{5}$ Thereby standard operating procedures and guidelines should be developed among all stake holders to regulate the conduct of research studies in dermatology involving collaborations between industry and academia. Focus should be there on the quality studies that adhere to International Standards. By developing and adhering to standards, research studies can be methodologically rigorous and reported consistently. Industry-sponsored collaborations are likely to be motivated by specific research questions involving commercial interests. Therefore acknowledgement and management of financial conflict of interest should be addressed before the initiation of the project. Proper transparency should be maintained in collaborative research and it should not bind investigator behavior. Industry must maintain transparency and ensure access data to researchers, in addition to balancing privacy, competitive and intellectual property considerations. ${ }^{5}$

The industry and the academic institution if converged, the discoveries will be effectively translated into products and will be advantageous for all academic institutions, the faculty members, industry and most importantly for society at large. Some examples of research collaborations in dermatology. The MGH/Harvard Cutaneous Research Centre was established in the year in 1989 as a result of a multiyear agreement between MGH/Harvard Medical School and Shiseido to conduct research on the skin and its adnexa using molecular biology techniques from multidisciplinary areas. Department of Dermatology at the University of Michigan received multiyear support from Johnson \& Johnson to carry out the fundamental research on the molecular basis of retinoid actions in the skin with the goal of designing better retinoids for therapeutic research. ${ }^{4}$ 


\section{REFERENCES}

1. Als-Nielsen, B, Chen, W, Gluud, C, Kjaergard, LL. Association of funding and conclusions in randomized drug trials: A reflection of treatment effect or adverse events? JAMA 2003;290:921-8.

2. Baird P. Getting it right: Industry sponsorship and medical research. CMAJ 2003;168:1267-9.

3. Danforth W (Task Force Chair): Task Force on Financial Conflicts of Interest in Clinical Research: Protecting Subjects, Preserving Trust, Promoting Progress-Policy and Guidelines for the Oversight of Individual Financial Interests in Human Subjects Research. 2001 Washington, DC: American
Association of Medical Colleges web reference, http://www.aamc.org/members/coitf/firstreport.pdf.

4. Bauer EA, Cohen DE. The changing roles of industry and academia. J Invest Dermatol. 2012 Mar;132(3 Pt 2):1033-6.

5. Prendergast MM, Abramovits W, Boguniewicz M, Lebwohl M, Tokar M, Tong KB. Look beyond financial conflicts of interest in evaluating industryacademia collaborations in burden-of-illness and outcomes research studies in dermatology. J Invest Dermatol. 2004 Sep;123(3):452-4.

Cite this article as: Pal S. Academia and industry collaboration in dermatology research. Int J Res Dermatol 2015;1:1-2. 